\title{
A maturity model for assessing the digital readiness of manufacturing companies
}

\author{
Anna De Carolis ${ }^{1}$, Marco Macchi $^{1}$, Elisa Negri ${ }^{1}$ and Sergio Terzi ${ }^{1}$ \\ ${ }^{1}$ Politecnico di Milano, Via Lambruschini 4/b, Milano, Italy \\ anna.decarolisepolimi.it; marco.macchiepolimi.it; \\ elisa.negriepolimi.it; sergio.terziepolimi.it
}

\begin{abstract}
The most profound technologies are those that disappear... They weave themselves into the fabric of everyday life until they are indistinguishable from it" wrote computer scientist and visionary Mark Weiser nearly 25 years ago in his essay "The Computer for the 21 st Century." It turns out he was right: in the age of "Industry 4.0", digital technologies are the core driver for the manufacturing transformation. In fact, the introduction of such technologies allows companies to find solutions capable to turn increasing complexity into opportunities for ensuring sustainable competitiveness and profitable growth. Nonetheless, the effective implementation in manufacturing still depends on the state of practice: it may slow down, or even worst, may prevent from implementation. Indeed, we assume that a minimum level of capabilities is required before implementing the digital technologies in a company. Based on this concern, our research question is "are manufacturing companies ready to go digital?". This paper wants to illustrate a "tool" to answer this question by building a maturity assessment method to measure the digital readiness of manufacturing firms. Based on the inspiring principles of the CMMI (Capability Maturity Model Integration) framework, we propose a model to set the ground for the investigation of company digital maturity. Different dimensions are used to assess 5 areas in which manufacturing key processes can be grouped: 1) design and engineering, 2) production management, 3) quality management, 4) maintenance management and 5) logistics management. Thus, the maturity model provides a normative description of practices in each area and dimension, building a ranked order of practices (i.e. from low to high maturity). A scoring method for maturity assessment is subsequently defined, in order to identify the criticalities in implementing the digital transformation and to subsequently drive the improvement of the whole system. The method should be useful both to manufacturing companies and researchers interested in understanding the digital readiness level in the state of practice.
\end{abstract}

Keywords: Digital readiness, Maturity model, Digital transformation, Industry 4.0.

\section{Research context and objective}

Industrial companies are digitizing essential functions within their internal operations processes, as well as with their partners along the value chain. In addition, they are 
enhancing their product portfolio with digital functionalities and introducing innovative, data-based services [1]. This is a journey they are taking towards a complete value chain transformation. At the end, successful companies will become true digital enterprises, with physical products at the core, augmented by digital interfaces and innovative services [1]-[3]. In a futuristic and disruptive vision, these digital enterprises will work together with customers and suppliers in industrial digital ecosystems [1]. To this aim, one of the main challenge industrial companies are now facing is to define their transformation roadmap. This is a strategic process that requires the engagement of different stakeholders (i.e. C-level managers, consultancy partners, etc.) in order to consistently obtain repeatable results. In order to build a valid roadmap-definition process, in literature it is possible to find many approaches. Among them, [4] identifies five main steps for addressing the strategic planning process: status quo analysis, strategic options generation, options assessment and evaluation, articulation of a strategic roadmap, and development of strategy. More specifically for digitalization, as stated in [5], manufacturing companies should undertake a comprehensive digital maturity assessment in order to have a transparent view on their current level of digital readiness. Indeed, a deep understanding of the current status of digitalization is a first step for a successful transformation. Once organizations have a clear perspective on their digital maturity, they should explore the corporate environment for opportunities triggered by digital technologies. Based on the identified opportunities, companies should develop a digital transformation roadmap, which has to be shared and accepted by all senior executives. Only at this time, companies would start investing to proceed in its digital transformation.

In order to support companies start defining their digitalization transformation roadmap, a model to analyze their status quo is needed. To this aim, a maturity assessment of digital readiness in manufacturing companies based on the inspiring principles of the CMMI (Capability Maturity Model Integration) framework is proposed. In fact, three application-specific purposes can be identified in literature ([6], [7], [8], [9]):

1. Descriptive purpose: maturity models with this purpose, want to assess the as-is situation of the organization/process;

2. Prescriptive purpose: a prescriptive model focuses on the domain relationships to performance and indicates how to approach maturity improvement in order to positively affect business value;

3. Comparative purpose: a comparative model enables benchmarking across companies; in particular, a model of this nature would be able to compare similar practices across organizations in order to benchmark maturity within different industries.

Even though these three types of maturity models can be seen as distinct, they are the evolutionary phases of a model's lifecycle. As a matter of fact, a model is descriptive in its first phase, so that a deeper understanding of the current domain situation is achieved. A model can then be evolved into being prescriptive as it is only through a sound understanding of the current situation that substantial and repeatable improvements can be made. Finally, a model, with comparative purposes, must be applied in a wide range of organizations in order to attain sufficient data to enable valid comparison [6]. In this regard, some authors ([10], [11], [12], [13], [14]) aim at using their created 
maturity models within frameworks, which allow the companies to have an integrative plan that assures the alignment of their processes with the desired maturity level. In particular, companies should use these maturity models to assess their maturity levels and to benchmark them with the ones of their competitors. In this way, it will be possible for them, firstly, to identify what desired level they have to reach and, secondly, to select some items, which have to be improved. In this way, a roadmap can be defined.

Some on-line tools exist, allowing companies to self-assess their readiness for the digital transformation. Nevertheless, even if these tools allow companies to assess maturity indexes indicating their level of digitalization (i.e. models are driven by descriptive purpose), they do not provide them a structured "guide" on how to encounter the digital transformation process basing on their current situation (i.e. according to a prescriptive purpose). After having performed some research, it is possible to state that, to the best of the knowledge reached, either on-line or in literature, a model able to "guide" manufacturing companies towards the digitalization has not been found.

\section{$2 \quad$ Building a maturity model}

As far as the methodological view of developing maturity models is concerned, most of the maturity models published lacked in a sound theoretical basis and methodology. Indeed, there is a little documentation on how to develop a maturity model that is theoretically robust, tested and widely accepted ([9]). Only in recent years, some authors suggested methods for the development of maturity models ([6], [15], [16], [17], [18], [19], [8]). Even though they created their own development framework with different characteristics, the same guidelines, which have to be followed for the construction of a maturity model, can be recognized among them. Indeed, comparing these frameworks, five common activities are identified: inception, elaboration, construction, deployment and maintenance ([9]).

During the inception phase, the main activities to perform are problems and participants identification, as well as planning and scoping goals. Successively, in the elaboration phase, the design strategy and the architecture of the model have to be determined. In the construction phase, the tool to measure the maturity of the object of interest is built and the procedures for its deployment and management are defined. In the last stage, the deployment phase, the maturity model and assessment tool are validated. If the model is accepted, it enters in a maintenance phase, were changes are managed and, if it is necessary, the model is updated ([9]).

\section{The digital readiness assessment maturity model}

In this section, the focus is on the activities carried out to develop the DREAMY (i.e. short name of Digital REadiness Assessment MaturitY model) and the related questionnaire. The model development of [6] was used as the framework for building the model. The phases "Design and Populate" of the overall framework are only analysed in the remainder of this paper. 


\subsection{Designing the maturity model}

\section{Architecture}

To define the model architecture, it was fundamental to identify the manufacturing relevant processes, within which these activities are performed, and that are strategic for the digital transformation. When structuring the manufacturing relevant processes, the first considerations done were about how they highly depend on the company's production strategy (i.e. Engineer-To-Order -ETO-, Make-To-Stock -MTS-, etc.). ETO companies, for example, can build their competitive advantage thanks to a perfect management of quotation and customer requirement comprehension phases, while MTS companies have to be very well organized in forecasting demand and in stock management processes. As the objective is not to focus on a single manufacturing company's strategy, a modular and scalable architecture was built, enabling to adapt to the needs, and thus assessment, of companies using different production strategies.

In order to make the architecture as general as possible, manufacturing company's processes were grouped in areas, which are strategic for the digital transformation. At the end, five main areas were identified: 1) Design and Engineering; 2) Production Management; 3) Quality Management; 4) Maintenance Management; 5) Logistics Management. Each process area can be considered as a self-contained module and therefore it is possible to add or remove one or more areas in case of they are not meaningful in certain industrial situations with no impact on the macro-structure foundation. Horizontally to these process areas, it interposes the Digital Backbone, within which all the information exchange processes inter-areas are covered.

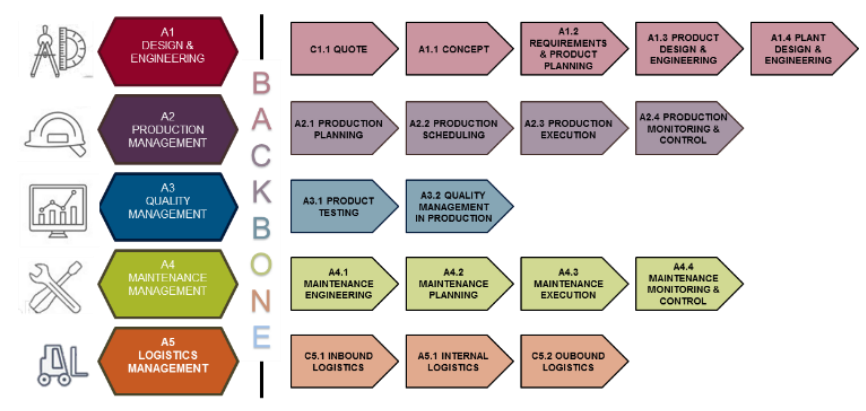

Fig. 1. DREAMY process structure

\section{Maturity levels}

Once the architecture is given, maturity levels are still undefined; they are however relevant issues in maturity assessment. Indeed, for the objective of this work, the digital readiness of a manufacturing company is defined through a scale of maturity levels. These levels describe a proper set of company capabilities, to provide a snapshot of their current (digital) abilities. The levels have been based on the inspiring principles of the CMMI framework [20], [21]. The main reason of this choice is that the CMMI provides a defined structure of maturity levels, specifying what are the 
capabilities a company has at each level. In this way, as the five-scale CMMI maturity levels provided a generic model to start from, they have been re-adapted in order to gather the definitions, and so the semantic, of the digital readiness maturity levels (see Table 1).

Table 1. Maturity levels' definition

\begin{tabular}{|l|l|}
\hline Maturity Level & \multicolumn{1}{c|}{ Description } \\
\hline ML1 & $\begin{array}{l}\text { The process is poorly controlled or not controlled at all, process management } \\
\text { is reactive and does not have the proper organizational and technological } \\
\text { "tools" for building an infrastructure that will allow repeatability / usability } \\
\text { / extensibility of the utilized solutions. }\end{array}$ \\
\hline ML2 & $\begin{array}{l}\text { The process is partially planned and implemented. Process management is } \\
\text { weak due to lacks in the organization and/or enabling technologies. The } \\
\text { choices are driven by specific objectives of single projects of integration } \\
\text { and/or by the experience of the planner, which demonstrates a partial ma- } \\
\text { turity in managing the infrastructure development. }\end{array}$ \\
\hline ML3 & $\begin{array}{l}\text { The process is defined thanks to the planning and the implementation of } \\
\text { good practices and management procedures. The management of the process } \\
\text { is limited by some constraints on the organizational responsibilities and / or } \\
\text { on the enabling technologies. Therefore, the planning and the implementa- } \\
\text { tion of the process highlights some gaps/lacks of integration and interoper- } \\
\text { ability in the applications and in the information exchange. }\end{array}$ \\
\hline $\begin{array}{l}\text { MEFINED } \\
\text { INTEGRATED }\end{array}$ & $\begin{array}{l}\text { Being the process built on the integration and on the interoperability of some } \\
\text { applications and on the information exchange, it is fully planned and imple- } \\
\text { mented. The integration and the interoperability are based on common and } \\
\text { shared standards within the company, borrowed from intra- and/or cross- } \\
\text { industry de facto standard, with respect to the best practices in industry in } \\
\text { both the spheres of the organization and enabling technologies. }\end{array}$ \\
LE & $\begin{array}{l}\text { The process is digital oriented and is based on a solid technology infrastruc- } \\
\text { ture and on a high potential growth organization, which supports - through } \\
\text { high level of integration and interoperability - speed, robustness and secu- } \\
\text { rity in information exchange, in collaboration among the company functions } \\
\text { and in the decision making. }\end{array}$ \\
\hline $\begin{array}{l}\text { ML5 } \\
\text { DIGITAL- }\end{array}$ &
\end{tabular}

Along the maturity levels, it is worth remarking the relevance of integration, either vertical or horizontal one, as well as intra- or inter-companies, and of interoperability: they are two primary levers to enable digital-orientation. Integration is a commonly known concept: it is the first systemic paradigm used to organise humans and machines at different levels [22], field, management and corporate level, to produce an integrated enterprise system. It has been recognized since long in its importance for the manufacturing chain within the networked enterprise, in order "to control and to manage the customised manufacturing of both goods and services as desired by the Internet society" [23]. Interoperability (Enterprise interoperability) is the "ability of enterprises and entities within those enterprises to communicate and interact effectively" [24]. This is an enabler of business collaboration (intra- or inter-companies), and it is not just a technology problem. Indeed, interoperability requires solutions to overcome barriers of different nature, i.e. conceptual, technological and organizational ones [24]. Nowadays, interoperability is clearly a relevant requirement that comes out along the journey towards the digital transformation. 


\begin{abstract}
Analysis dimensions
From what already defined in the maturity levels, it is clear that, when evaluating the digital capabilities of a company, not only the technologies used to support the processes have to be considered. Indeed, without structured processes and defined organization structures, a company will not be able to exploit the opportunities these technologies offer. From these considerations, from the evidences presented in the literature and considering the objective of the maturity model itself, it was decided to evaluate the digital readiness of manufacturing companies through four analysis dimensions: Process, Monitoring and Control, Technology and Organization. The decision of considering these analysis dimensions was made mainly taking into account the units of analysis of the DREAMY, which are manufacturing relevant processes. To this aim, it was decided to assess: 1) the way in which these processes are carried out (Process dimension); 2) the way in which these processes are monitored and controlled through the evaluation of feedbacks received from their execution (Monitoring and Control dimension); 3) the technologies that support these processes (Technology dimension); 4) the organizational structures behind these processes (Organization dimension).
\end{abstract}

The maturity model and its use for the status quo analysis

The maturity model is synthesized in Fig. 2. The model is usable, as a first function, for descriptive purposes: the maturity indexes are relevant elements for describing the as-is situation of a manufacturing company according to the different dimensions and areas considered.

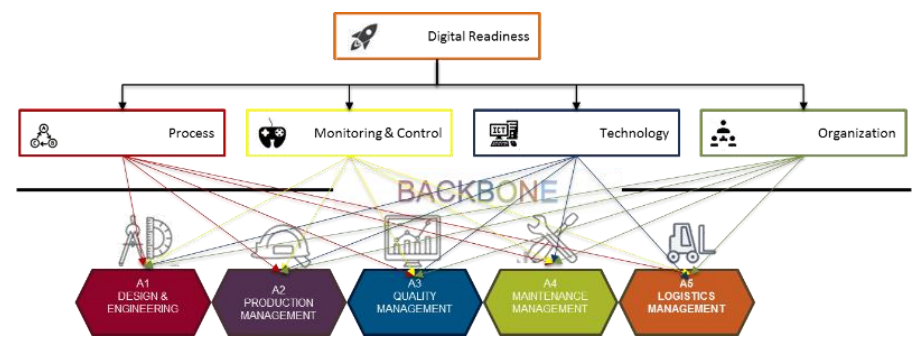

Fig. 2. Representation of the maturity indexes calculation

\title{
3.2 Populating the maturity model
}

The findings from design - i.e. architecture, maturity levels and analysis dimensions were validated with academia and company experts. The output of this phase was the first realise of the Digital Readiness Questionnaire. Within the questionnaire, for each question a standard normative of answers was developed. These standard answers were structured according to an increasing level of maturity, following the five-scale digital readiness maturity levels previously described. To define the answers, considerations from company experts were blended with the ones of academia experts and literature findings. This allowed exploiting the maturity model as theoretical framework in order to inform the questionnaire construction. In particular, such a construction was done by 
synthesizing the specific knowledge from experts and literature in different fields (i.e. design and engineering, production management, etc. according to the architecture of Fig. 1), collected and organized according to the different maturity levels and analysis dimensions. An example of the question related to Quality Management area is provided below:

Does the organisation perform regular reviews regarding problems related to product tests and quality?

- No, no review is performed $M L 1$

- Yes, reviews are performed but not by experts in the field $M L 2$

- Yes, reviews are performed by experts in the field, but still not systematically $M L 3$

- Yes, reviews are performed by experts in the field, from involved company departments / functions $M L 4$

- Yes, reviews are performed by experts in the field, from involved company departments / functions, also including suppliers and OEMs where necessary $M L 5$

Thanks to the information gathered through the execution of the questionnaire, it is possible to assess the company's digital readiness with the series of maturity indexes already presented in Fig. 2.

\section{Conclusions}

It is now important to discuss how the DREAMY can be used for road-mapping. Indeed, it is important to underline that although the model's objective is to help manufacturing companies to assess their processes so to figure out how they are ready for the digital transformation, it also helps in developing their transformation roadmap. Therefore, maturity assessment has to be considered just the first step of an overall approach. The next development steps regard a concrete overview on what are the suggested actions to undertake in order to improve processes' maturity. The expected output will be a list of opportunities enabled by the digitalisation that the analysed company can take advantage of to overcome the identified needs.

\section{References}

[1] P. GMIS, “Industry 4.0: Building the Digital Industrial Enterprise," 2016.

[2] J. Lee, B. Bagheri, and C. Jin, "Introduction to cyber manufacturing," Manuf. Lett., vol. 8, 2016.

[3] M. E. Porter and J. E. Heppelmann, "How smart, connected products are transforming competition," Harvard Business Review, no. November 2014. 2014.

[4] D. Kukreja, "Strategic Planning: a Roadmap To Success," Ivey Business Journal Online, 2013.

[5] Capgemini Consulting, "Digitizing Manufacturing : Ready, Set, Go !," 2014.

[6] T. De Bruin, R. Freeze, U. Kaulkarni, and M. Rosemann, "Understanding the Main Phases of Developing a Maturity Assessment Model,” in Australasian Conference on Information Systems (ACIS), 2005, pp. 8-19.

[7] J. Pöppelbuß and M. Röglinger, "What makes a useful maturity model? A framework of general design principles for maturity models and its demonstration in business process management," Ecis, p. Paper28, 2011. 
[8] A. M. Maier, J. Moultrie, and P. J. Clarkson, "Assessing organizational capabilities: Reviewing and guiding the development of maturity grids," IEEE Trans. Eng. Manag., vol. 59, no. 1, 2012.

[9] G. A. Garcia-Mireles, M. A. Moraga, and F. Garcia, "Development of maturity models: A systematic literature review," in Evaluation Assessment in Software Engineering (EASE 2012), 16th International Conference on, 2012, pp. 279-283.

[10] J. H., A. A., D. R., April A.a d Hayes, "Software Maintenance Maturity Model (SM" $\left.{ }^{\mathrm{mm}}\right)$ : The software maintenance process model," J. Softw. Maint. Evol., vol. 17, no. 3,2005.

[11] J. Batenburg, R., Helms, R. W., \& Versendaal, "PLM roadmap: stepwise PLM implementation based on the concepts of maturity and alignment," Int. J. Prod. Lifecycle Manag., vol. 1, no. 4,2006.

[12] B. Curry, E., \& Donnellan, "Understanding the maturity of sustainable ICT," Green Bus. Process Manag. Springer Berlin Heidelberg., pp. 203-216, 2012.

[13] I. Boughzala and G.-J. de Vreede, "Evaluating Team Collaboration Quality: The Development and Field Application of a Collaboration Maturity Model," J. Manag. Inf. Syst., vol. 32, no. 3, pp. 129$157,2015$.

[14] M. Sopelana, A., Flores, M., Martinez, L., Flores, K., \& Sorli, "The application of an assessment tool for lean product development: an exploratory study in Spanish Companies," in Engineering, Technology and Innovation (ICE), 2012 18th International ICE Conference, 2012, pp. 1-10.

[15] T. Mettler and P. Rohner, "Situational maturity models as instrumental artifacts for organizational design," Proc. 4th Int. Conf. Des. Sci. Res. Inf. Syst. Technol. - DESRIST '09. Artic. No. 22, no. May 06-08, pp. 1-9, 2009.

[16] J. Becker, R. Knackstedt, and J. Pöppelbuß, "Developing Maturity Models for IT Management," Bus. Inf. Syst. Eng., vol. 1, no. 3, pp. 213-222, 2009.

[17] C. Salviano, A. Zoucas, J. Silva, M. A. Alves, C. Wangenheim, and M. Thiry, "A Method Framework for Engineering Process Capability Models," Softw. Process, vol. 36, no. September, pp. 2-4, 2009.

[18] M. Van Steenbergen, R. Bos, S. Brinkkemper, I. Van De Weerd, and W. Bekkers, "The design of focus area maturity models," in CEUR Workshop Proceedings, 2010, vol. 662

[19] A. von Wangenheim, C. G., Hauck, J. C. R., Salviano, C. F., \& von Wangenheim, "Systematic literature review of software process capability/maturity models," in INTERNATIONAL CONFERENCE ON SOFTWARE PROCESS IMPROVEMENT AND CAPABILITY DETERMINIATION-SPICE, 2010.

[20] M. Macchi and L. Fumagalli, "A maintenance maturity assessment method for the manufacturing industry,” J. Qual. Maint. Eng., vol. 19, no. 3, pp. 295-315, 2013.

[21] M. Macchi, L. Fumagalli, S. Pizzolante, A. Crespo, J. F. Marquez, and G. Fernandez, "Towards eMaintenance: maturity assessment of maintenance services for new ICT introduction," in APMS 2010 international conference on Advances in Production Management Sys-tems, 2010.

[22] F. B. Vernadat, Enterprise modelling and integration, principles and applications. 1996.

[23] G. Morel, H. Panetto, M. Zaremba, and F. Mayer, "Manufacturing Enterprise Control and Management System Engineering: Paradigms and Open Issues," Annu. Rev. Control, vol. 27 II, pp. 199-209, 2003.

[24] ISO 11354-1:2011 - Part 1: Framework for enterprise interoperability, Advanced automation technologies and their applications - Requirements for establishing manufacturing enterprise process interoperability. 2011. 